IV Congreso Internacional Estética y Política Poéticas del desacuerdo para una democracia plural 16 y 17 de octubre. Valencia

Doi: http://dx.doi.org/10.4995/CEP4.2019.10513

\title{
La caricatura política norteamericana de derechas en Internet: repercusión y difusión digital de la obra de Ben Garrison
}

\author{
Enrique García Parreño
}

Máster en Producción Artística, Universitat Politècnica de València. enric.garcia.96@gmail.com

\begin{abstract}
This work tries to show the repercussion and diffusion of the political illustrations of the American cartoonist Ben Garrison on the Internet as an example of a right-wing activism carried out from a traditional technique, the editorial cartoon, in a current medium, the Internet. With all this, the objective is to demonstrate, from this specific case, the benefits and harms of freedom of expression in the net, as well as the power of metaphorizing emotions to build virtual communities. When addressing this writing, first of all, the motivations of its beginning as an independent political cartoonist are explained; secondly, the reasons for the viralization of his work are established; and finally, the reception of his cartoons from two sides is compared. On the one hand, the reproduction and defense of his work from the US nationalpopulist movement in social networks and alternative pro-Trump digital newspapers. On the other hand, outside this, where his work, considered "politically incorrect" is criticized and manipulated anonymously from, mainly, the forums "4chan" and "8chan" in favor of racism to damage the image of the cartoonist and reinforce the North American right-wing speeches
\end{abstract}

Keywords: artivism, alt-right, cartoon, United States, Internet, freedom of expression, nationalpopulism, journalism, populism

\begin{abstract}
Resumen
El presente trabajo trata de mostrar la repercusión y difusión de las ilustraciones políticas del caricaturista estadounidense Ben Garrison en Internet como ejemplo de un activismo de derechas realizado desde una técnica tradicional, la caricatura editorial, en un medio actual, Internet. Con todo esto, el objetivo es demostrar, desde este caso concreto, los beneficios y perjuicios de la libertad de expresión en la red, así como el poder de la metaforización de las emociones para construir comunidades virtuales. A la hora de abordar este trabajo, en primer lugar, se explican las motivaciones de su inicio como caricaturista político independiente; en segundo lugar, se establecen las razones de la viralización de su obra; y, finalmente, se compara la recepción de sus caricaturas desde dos flancos. Por una parte, la reproducción y defensa de su obra desde el movimiento nacionalpopulista estadounidense en redes sociales y periódicos digitales alternativos pro-Trump. Por otra parte, fuera de este, en donde su obra, considerada, "políticamente incorrecta» es criticada y manipulada anónimamente desde, principalmente, los foros «4chan» $y$ «8chan» en pro del racismo para perjudicar la imagen del caricaturista y reforzar los discursos ultraderechistas estadounidenses.
\end{abstract}

Palabras clave: artivismo, alt-right, caricatura, Estados Unidos, Internet, libertad de expresión, nacionalpopulismo, periodismo, populismo 


\section{Introducción y objetivos}

Actualmente, dirigentes como Donald Trump o Marine LePen, partidos como Alternativa para Alemania, o fenómenos como el brexit, son ejemplos reconocibles de lo que es el nacionalpopulismo. El denominador común entre sus seguidores y líderes es que dan prioridad a la cultura y los intereses de la nación, y prometen dar voz a quienes sienten que las élites, a menudo corruptas y distantes, los han abandonado e incluso despreciado (Eatwell y Goodwin, 2019, p.11). A lo largo de su libro, estos autores desarrollan las principales preocupaciones compartidas entre los seguidores de este movimiento internacional. A grandes rasgos, desconfían de las grandes instituciones y los partidos políticos mayoritarios por la distancia, cada vez mayor, entre estos y el votante; esta distancia se debe a que este último ve que se le está dando prioridad a grupos que no son el suyo; luego, este teme que el gobierno destruya la comunidad y la identidad histórica nacional en pro de lo políticamente correcto. Finalmente, a raíz de este temor, los votantes creen que han dejado de tener voz, ya no se identifican con sus dirigentes políticos, sienten incertidumbre por su futuro más próximo y abandonan la lealtad a los partidos mayoritarios para caer en la apatía política o en la búsqueda de nuevas propuestas políticas. Entonces, ante la amenaza de la desintegración de la nación, creen que el Estado debería dar prioridad a aquellos que han gastado toda su vida contribuyendo al Fondo Nacional; además, demandan políticos más comprensivos y parecidos con el ciudadano medio y menos con las élites políticas y económicas.

Por lo tanto, a pesar de que surgiera mucho antes, no es de extrañar que el nacimiento del movimiento nacionalpopulista suela señalarse en la crisis financiera de 2008 y la posterior Gran Recesión; así pues, el contexto que trata el presente trabajo, Estados Unidos, es un ejemplo de ello, ya que el rescate financiero del Congreso a los grandes bancos en 2008 hizo enfurecer a millones de estadounidenses que vivieron la pérdida de su trabajo y el rechazo de sus dirigentes políticos en pro de los intereses de una supuesta élite política y económica. Este amplio grupo de personas fueron los que alentaron el movimiento nacionalpopulista en los Estados Unidos; el cual, como su nombre indica, tiene sus bases en el populismo, más el factor nacional. Uno de estos ciudadanos es Ben Garrison, artista y caricaturista político independiente de derechas, quien decide empezar a publicar en 2009, en su blog personal, dibujos que denuncian la corrupción de la Reserva Federal por parte de una élite mundial. Sin embargo, por querer informar a sus compatriotas, haciéndoles ver la verdadera naturaleza de su gobierno, su posterior apoyo a Donald Trump, aquel en quien confía para luchar contra la corrección política y la élite corrupta, le hizo situarse cerca de la alt-right, movimiento de extrema derecha estadounidense. Pese a que Garrison se ha declarado reiteradas veces como un libertario conservador, sus dibujos, al ser compartidos on-line por determinadas plataformas y personalidades, produjeron que un gran número de internautas lo relacionara con ideologías extremas, como el nazismo, y cargasen masivamente contra él. Hagamos un inciso. Cabe apuntar que no se puede reducir el nacionalpopulismo a un tipo de votante o a una única causa; matizar estas cuestiones desbordaría los límites del presente escrito y tan solo se explicará la sintonía de las preocupaciones de Ben Garrison con las de este movimiento. Por lo tanto, frente al abanico de tipos de votantes nacionalpopulistas, se puede situar a Garrison dentro del perfil de los «hombres mayores blancos y enfadados», grupo que ha sido, y es el estereotipo más extendido del típico elector nacionalpopulista.

Frente a lo anteriormente expuesto, este trabajo intenta describir, a grandes rasgos y a través de la figura de Ben Garrison, el perfil de uno de los tipos de seguidores del movimiento nacionalpopulista estadounidense. A continuación, se explica la utilidad de su actividad artística a la hora de ayudar a dicho movimiento a construir y reforzar una comunidad de indignados, de derechas, en Internet, aprovechando las ventajas que este ofrece en cuanto al poder de difusión de contenido. Sin embargo, también se muestra la otra cara de la moneda, esto es, nombrar aquellos peligros que tiene la exposición y reivindicación de ideas e imágenes, en este caso de claro sesgo conservador, y su malinterpretación hacia ideologías extremistas. Para ello, tras definir a grandes rasgos el perfil ideológico de Ben Garrison, apoyado por declaraciones personales (en sus libros y en diversos sitios de Internet) y argumentado en las bases qué es lo que se entiende por populismo y nacionalpopulismo según determinados autores, se procede a medir distancias entre estas últimas y otras ideologías extremistas, para defender que Ben Garrison, y el perfil que encarna, no es fascista. 


\section{Re-inicio como caricaturista político: resistencias y ataques contra el gobierno}

Ben Garrison (nacido en 1957) tras obtener el bachiller universitario en letras, un Bachelor of Arts, en Bellas Artes e Historia del Arte por la Angelo State University, empezó su carrera como dibujante de prensa en el diario San Angelo Standard-Times (San Angelo, Texas) y en 1983 trabajó de director artístico en el periódico Seattle Post-Intelligence (Seattle, Washington) hasta 1997. Posteriormente ha trabajado como diseñador gráfico independiente desde su propia marca, Garrison Graphics, ahora rebautizada GrrrGraphics, junto con su esposa en Lakeside (Montana). Pero no fue hasta 2009 cuando decidió retomar su carrera de caricaturista político, en solitario, tras haber perdido su trabajo, al igual que otros millones de estadounidenses, como consecuencia de la crisis financiera de 2008. Entonces, tras ver la preferencia del gobierno por salvar a los grandes bancos antes que cumplir la demanda de no hacerlo por parte de millones de estadounidenses, comprendió que el poder político había dejado de ser de los ciudadanos en pro de una oligarquía globalista de élites (Garrison, 2015). Dando como resultado la sustitución de una verdadera economía de mercado libre (Garrison, 2015), a un sistema para enriquecer a aquellos que dirigen su propio casino (Garrison, 2015). Luego, harto de que no ocurriese nada, decidió alzar la voz para que este mensaje fuera escuchado por el mayor número de estadounidenses posible, animando a sus compatriotas a hacer lo mismo desde otros medios alternativos, sobre todo desde Internet, ya que los medios de comunicación dominantes han perdido su credibilidad por haberse convertido en los portavoces de corporaciones globales (Garrison, 2015). Por lo que él ha hecho al respecto, recuerda en 2017: Consideré mi deber patriótico denunciar la corrupción en-tu-cara que muestran los banqueros corruptos centrales. [...] No comencé a dibujarlos por fama, sino por expresar ira por lo que le estaba sucediendo a mi país (Garrison, 2017). Aclara en una entrevista realizada para Vice en 2016: Señalo su codicia [la de la Reserva Federal] por el dinero y el poder mediante el uso de metáforas. Por ejemplo, una [caricatura] que dibujé reciente se llamaba "La danza del dólar". Presentaba a Janet Yellen bailando con un gato gordo de Wall Street. Estaban disfrutando de su vals de clase alta, pero sus pies estaban pisoteando a la clase media, la cual se está yendo (Sunderland, 2016).

Por lo que respecta al uso de las metáforas, o la metaforización, la actividad artística de Ben Garrison ayudó, en mayor o menor medida y a largo plazo, al desarrollo del movimiento nacionalpopulista en Estados Unidos. El nexo entre ambos dos es la crisis del 2008, ya que, como se ha comentado anteriormente, el gobierno de este país sufrió una crisis institucional al ignorar las demandas de la mayoría de sus ciudadanos, entre ellos el caricaturista. Luego, estos se sintieron rechazados por sus dirigentes políticos y reclamaron un gobierno que realmente les representase y estuviese de su lado. Ahora bien, pese a querer cambiarlo, los millones de estadounidenses frustrados no eran un grupo cohesionado, ya que existían matices entre sus peticiones individuales que los diferenciaban y distanciaban. Entonces, si este conjunto de demandas está disperso, no se puede concebir una fuerza política representativa sólida. Para poder llevarlo a cabo, explica José Luis Villacañas en su ensayo Populismo, todas las demandas tienen que unirse en una. No obstante, añade: No se trata de que esa demanda unitaria sea la clave para resolver todas las demás, sino que represente metafóricamente a todas las demás (Villacañas, 2017, p.66). Esto es, el marco común que plantea el movimiento populista para que interactúen todas las demandas individuales. Pero si gran parte de estas no se atienden, como en este caso, estalla una crisis institucional y se quiebra el imaginario y el potencial de inclusión nacional. Ante esta situación, el populismo tiene que hacer entender a los votantes que todo el aparato institucional no atiende a sus demandas y actúa en beneficio de una élite, la cual no representa al pueblo. Tras dejar esta cuestión bien clara, se pueden establecer dos grupos bien diferenciados: los instalados (las instituciones) y los excluidos (la gente); de esta forma, es más fácil para el votante identificarse con el segundo grupo, formar una totalidad y compartir el sentimiento de abandono. Ahora bien, para que este discurso se asiente, la prioridad del movimiento populista es convencer a los excluidos de lo que son y concienciarlos de esta crisis institucional. En el caso del populismo, a través de la retórica oral; en el de Ben Garrison, mediante la retórica visual. Para empezar, al dirigirse al ciudadano medio, lleva a cabo una política comunicativa imprecisa y simplificada basada en lo espectacular y lo sentimental, ya que, al dar por supuesto el analfabetismo político de la masa, se dirigirse a esta mediante un lenguaje figurativo que busca despertar sus afectos y producir vínculos sociales dentro de una comunidad de excluidos. Posteriormente, si ha decidido denunciar la corrupción de un gobierno elitista al mayor número de compatriotas, se entiende que haya escogido Internet como plataforma de difusión y que haya usado un lenguaje visual claro, sencillo y controvertido en sus dibujos. 
La actual Web 2.0 le ha permitido a Ben Garrison crear su propio medio de publicación, fuera de cualquier editorial, donde comparte metáforas visuales que son el señuelo donde otros usuarios se reconocen ideológicamente. También, debido a lo intuitivo de su uso, estos usuarios han viralizado la obra de Garrison a través de diversas redes sociales; por lo tanto, esta multitud de internautas tiene el poder de reproducir, extender y asentar en Internet un imaginario alternativo al que ofrecen los medios y canales de comunicación tradicionales y/o mayoritarios; estos, recuérdese, calificados por el caricaturista como portavoces de corporaciones globales (Garrison, 2015).

Como se ha explicado anteriormente, las demandas individuales han de unirse metafóricamente en una. Sin embargo, esa totalidad de las demandas sigue siendo una representación vacía. [...] Por eso es preciso que esa representación se encarne (Villacañas, 2017, p.76). Esta es la función del líder: representarlas personalmente y unificarlas simbólicamente. Bien podría haber sido el candidato republicano a la presidencia Rand Paul pero tras su abandono, Ben Garrison apoyó, y apoya, a Donald Trump por tres principales razones: en primer lugar, su lucha contra la corrección política; en segundo lugar, y relacionado con la anterior, su actitud, confianza y alarde de ser un empresario capaz de negociar con el gobierno para drenar el pantano, lo que le hace estar alejado de la élite política estadounidense. En palabras del propio caricaturista, es algo que muchos hemos querido durante mucho tiempo: un candidato populista que también es nacionalista, NO otro títere globalista (Garrison, 2016). Y, en tercer lugar, de entre todos los candidatos, confiesa el caricaturista, es el más divertido de dibujar (Garrison, 2017). En sus caricaturas lo representa idealizado con un cuerpo tonificado y una densa melena para remarcar su actitud, confianza y alarde ante sus adversarios políticos, ridiculizados descaradamente en sus dibujos; por lo tanto, el trabajo de Garrison ayuda a fortalecer la imagen pública de Trump como un líder patriótico, apuesto y carismático que siempre gana, impecable, contra la élite corrupta.

\section{Recepción y difusión de su obra; apoyos y ataques hacia su persona}

Desde su regreso en 2009 hasta la actualidad, la popularidad de sus caricaturas y su persona han ido aumentando constantemente. Hoy en día, 10 años después, alrededor de 70.000 personas siguen su página de Facebook; 185.000 en Twitter; y 36.000 en Instagram. En 2016, durante la campaña electoral a la presidencia de los Estados Unidos, el caricaturista se dedicó a informar a sus seguidores, mediante caricaturas de una sola viñeta, sobre los logros de Donald Trump y los fracasos de su rival, Hillary Clinton. Su intención provocadora contra lo políticamente correcto atrajo la curiosidad de muchos, la admiración de unos y el odio de otros; además, su estilo realista, haciendo fácilmente reconocible a quien dibuja, y su rotundidad en metaforizar lo que piensa al respecto de determinados acontecimientos o personajes públicos, hizo que sus dibujos fuesen entendidos por un público muy amplio. Y, por supuesto, el uso intuitivo de Internet y la facilidad de compartir una imagen por las redes sociales, fueron claves para viralizar su controvertida obra, hasta el punto de haber sido publicada en redes sociales por el mismo Donald Trump y sus colegas republicanos, periodistas de medios alternativos como Alex Jones y otras personalidades como Kylie Jenner. Sin embargo, la lista es más extensa. Nombra en su página web aquellos medios donde le han entrevistado, escrito artículos o publicado su trabajo: Breitbart, Washington Times Newspaper, InfoWars, Politico, Slate, ZeroHedge, The Federalist Papers, MichaelSavage.com, Politico.com, Big League Politics.com, Patrick J. Buchanan.org (GrrrGraphics). Si Ben Garrison ha aparecido, bien sea en primera o en tercera persona, en estos medios, cabe destacar su estrecha relación y presencia con el más relevante de todos ellos: Breitbart News. Se trata de una web de noticias y opinión fundada a mitad de 2007 por Andrew Breitbart, columnista y editor republicano que, tras su muerte en 2012, le sucedió Steve Bannon, consejero de Trump durante la primera mitad de 2017. Breitbart News ha entrevistado a Ben Garrison, ha ilustrado varias noticias con sus caricaturas y ha retratado una nueva sección en 2015, Breitbart Tech, representando a Milo Yiannopoulos, coeditor de dicha sección, vestido con una armadura, luchando contra un dragón de seis cabezas que encarna a los Social Justice Warriors y la corrección política (Yiannopoulos y Dulis, 2015). Por lo que respecta tanto a Bannon como Yiannopoulos, estos se sitúan ideológicamente en lo que Marcos Reguera llama la facción Breitbart o la Alt Light; esto último para diferenciar su moderación con el radicalismo de la verdadera alt-right, liderada por Richard B. Spencer. Los miembros de la Alt Light, añade Marcos Reguera, se definen como libertarios conservadores o anarco-capitalistas conservadores; tienen una visión xenófoba, no le dan tanta importancia a la raza como la cultura y la religión, y cargan contra el feminismo y el islam, ambos considerados amenazas contra la libertad de los estadounidenses (Reguera, 2017). 
En otro sentido, lo que caracteriza a muchos de ellos, en sintonía con Trump y Garrison, es recurrir a la irreverencia y al humor para presentar sus ideas más controvertidas. La ironía es un arma al servicio de una guerra contra el pensamiento políticamente correcto, en donde toda acción o declaración están justificadas y amparadas bajo el manto de una ilimitada libertad de expresión (Reguera, 2017). Para hacerse una idea de donde se sitúa ideológicamente Breitbart en el mapa del periodismo estadounidense, un estudio sobre más de 1,25 millones de historias publicadas por esta web, entre el 1 de abril de 2015 y el día de las elecciones, muestra que una red de medios de derecha anclada alrededor de Breitbart se desarrolló como un sistema de medios distinto y aislado, utilizando las redes sociales como columna vertebral para transmitir una perspectiva hiperpartidista al mundo (Benkler, Faris, Roberts, Zuckerman, 2017). Por lo tanto, Breitbart se ha convertido en el centro de un ecosistema mediático de derechas, al que se le ha acusado reiteradas veces de difundir fake news y tachado de conspiranoico; esto último junto a la corrupción y la traición de los medios, son los tópicos más recurrentes de sus titulares. Sin embargo, también al populismo se le ha tachado de conspiranoico por defender que existe una conspiración de las élites frente al pueblo. Se trata, en definitiva, de la acusación de hipersimplificar la realidad, una acusación que perseguirá hasta el día de hoy a todo aquel que sea tachado de populista (D’Eramo, 2013, p.26).

Sin embargo, no solo le han acusado a los populistas de conspiranoicos, también de fascistas y antisemitas. Esto es debido a que movimientos extremos, como la alt-right en Estados Unidos, se han refugiado tras el populismo, un movimiento que, al abarcar una gran variedad de ideologías y de territorios, deviene un concepto muy flexible y útil tras el que operar, lo que conlleva a agrupar apresuradamente al populismo o al nacionalpopulismo con ideologías extremas como el nazismo. No es de extrañar que muchos de los seguidores de Ben Garrison, pese a que ha declarado reiteradas veces que es un libertario conservador, le viesen como un verdadero nazi y cargasen contra él. No obstante, una gran parte de internautas aprovechó la confusión y su mala reputación para articular una campaña de odio contra su persona. Esto empezó el primer año de su regreso, en 2009, por parte de usuarios de las plataformas 4chan y 8chan; quienes crearon un alter ego antisemita del caricaturista llamado Zyklon Ben, bien sea por motivos políticos o por otros más superficiales. Esto consistió en fotomontajes de su rostro en uniformes nazis, publicación de datos falsos y controvertidos en blogs y manipulación de sus caricaturas para que expresasen un rotundo mensaje antisemita, poniendo a la figura del judío como el auténtico conspirador. Todo esto, llegó a aparecer como primer resultado en las búsquedas de Google si se buscaba «Ben Garrison»; luego, este alter ego repercutió más allá de las pantallas, hiciendo que perdiese ofertas de trabajo por su fama de antisemita. Declaró en una entrevista que, por entonces, trataba de emprender acciones legales contra estos usuarios y Christopher Poole, propietario de 4chan, al que le veía como el alentador de esta situación (Caldwell, 2015). Sin embargo, poco había que hacer contra aquellos que, anónimamente, difunden su alter ego: no hay forma de hacerlos legalmente responsables de sus acciones y la ayuda legal es extremadamente costosa. Tras la publicación de su libro, Rogue Cartoonist, empezó a tratar los ataques de estos internautas con humor en vez de ira. Caricaturizó a los propietarios de los foros 8 chan y 4chan, publicando cada caricatura en su respectivo foro; no obstante, al primero le gustó, pero al segundo no. Esto condujo a que en 8 chan consiguiera más seguidores que en 4chan, ya que, Christopher Poole se aseguró de que se siguiera publicando en su foro contenido de Zyklon Ben (Caldwell, 2015).

\section{Conclusiones}

Estando en el borde del precipicio de estas páginas, cabe tomar aire y esbozar una serie de preguntas antes de saltar de él. En primer lugar, ¿qué es populismo? Marco D’Eramo en El populismo y la nueva oligarquía, recuerda cuando Richard Hofstadter, autor de The Age of Reform, etiquetó como antisemitas a los populistas, aquellos del finisecular Partido del Pueblo, basándose en escasísimas pruebas documentales. Esta anécdota le sirve para ilustrar que, aun a día de hoy, los populistas continúan cargando con la etiqueta de antisemitas. Y esto es debido a la vaguedad y la indeterminación de la etiqueta «populismo», y vista la variadísima heterogeneidad de movimientos y partidos a los que se coloca (D’Eramo, 2013, p.27). Sin embargo, cierto es que movimientos de extrema derecha utilizan el populismo como trinchera; lo cual, complica aún más la ecuación. En efecto, coincidiendo con D’Eramo, Eatwell y Goodwin, hay un serio problema sobre cómo se piensa acerca del populismo y la facilidad de relacionarlo con los extremos. 
En segundo lugar, ¿se puede hablar de prácticas artísticas populistas? Esto es, ¿se puede hablar de una metodología populista en artes? En el presente trabajo se ha señalado un posible nexo: la metaforización. Y quizás otros dos más, la simplificación del lenguaje y la espectacularidad. Todo ello, con un posible sentido hacia la construcción y fortalecimiento de comunidades. Finalmente, ¿cabe un activismo de derechas en Internet? Se habrá leído o escuchado, con algún tinte a teoría conspiratoria, desde cierto sector de la derecha, que las principales redes sociales tienen un sesgo anti-conservador y que han ido eliminando perfiles de organismos y personalidades sin ninguna justificación. El gobierno de Trump, ante el cierre de una de sus páginas web dedicada a que los ciudadanos compartiesen sus opiniones (White House), ha decidido poner lo siguiente: Este typeform ahora está cerrado. LAS PLATAFORMAS DE MEDIOS SOCIALES deben promover LA LIBERTAD DE EXPRESIÓN. Sin embargo, muchos estadounidenses han visto sus cuentas suspendidas, prohibidas o denunciadas de manera fraudulenta por "infracciones" poco claras de las políticas del usuario. El 15 de mayo [de 2019], el presidente Trump pidió a los estadounidenses que compartan sus historias de presuntos prejuicios políticos. La Casa Blanca recibió miles de respuestas. - ¡Gracias por prestar su voz!

\section{Referencias}

Benkler, Y., FARIS, R., Roberts, H., Zuckerman, E. (2017). "Study: Breitbart-led right-wing media ecosystem altered broader media agenda" en Columbia Journalism Review, 3 de marzo. 〈https://www.cjr.org/analysis/breitbart-media-trump-harvard-study.php> [Consulta: 13 de septiembre de 2019]

CALDwell, D. (2015). "Q\&A with Ben Garrison” en Know Your Meme, 18 de mayo. <https://knowyourmeme.com/blog/interviews/qawith-ben-garrison> [Consulta: 13 de septiembre de 2019]

D’eramo, M. (2013). “El populismo y la nueva oligarquía”. New Left Review, Vol. 2013 (82), pp.7-40. <https://newleftreview.es/issues/82/articles/marco-d-eramo-el-populismo-y-la-nueva-oligarquia.pdf> [Consulta: 14 de septiembre de 2019]

Eatwell, R. Y Goodwin, M. (2019). Nacionalpopulismo. Por qué está triunfando y de qué forma es un reto para la democracia. Barcelona: Península.

GARRISON, B. (2015). Rogue Cartoonist: The Internet Perils of a Citizen-Muckraker. Pennsauken: Bookbaby.

GARRISON, B. (2016). "Ben Garrison AMA" en Reddit, 13 de abril. <https://www.reddit.com/r/The_Donald/comments/4emi5x/ben_garrison_ama/> [Consulta: 13 de septiembre de 2019]

GARRISON, B. (2017). "Ben Garrison Spicy AMA" en Reddit, 5 de abril. <https://www.reddit.com/r/The_Donald/comments/63i1wg/ben_garrison_spicy_ama/> [Consulta: 13 de septiembre de 2019]

Garrison, B., Norton, T. ET AL. (2017). The 2016 Presidential Election Collection: Cartoons by Ben Garrison. Lakeside: www.grrrgraphics.com.

GRRRGRAPHICS. Media. <https://grrrgraphics.com/media> [Consulta: 13 de septiembre de 2019]

Reguera, M. (2017). "Alt Right: radiografía de la extrema derecha del futuro" en Ctxt, 105. Madrid: Revista Contexto. <https://ctxt.es/es/20170222/Politica/11228/Movimiento-Alt-Right-EEUU-Ultraderecha-Marcos-Reguera.htm> [Consulta: 13 de septiembre de 2019]

Sunderland, M. (2016). “The Anti-Vaxx Conspiracy Theorist Whose Cartoons Have Entranced Kylie Jenner” en Vice, 14 de marzo. <https://www.vice.com/en_us/article/wnwmyy/kylie-jenner-anti-vaxx-conspiracy-theory-tweet> [Consulta: 13 de septiembre de 2019]

ViLlacañas, J.L. (2017). Populismo. Madrid: La Huerta Grande.

WHITE House. This typeform is now closed. <https://whitehouse.typeform.com/to/Jti9QH> [Consulta: 13 de septiembre de 2019]

Yiannopoulos, M. Y Dulis, N. (2015). "Welcome to Breitbart Tech, A New Vertical Covering Tech, Gaming and Internet Culture" en Breitbart, 27 de octubre. <https://www.breitbart.com/tech/2015/10/27/welcome-to-breitbart-tech-a-new-vertical-covering-techgaming-and-internet-culture/> [Consulta: 13 de septiembre de 2019] 